\title{
Aktivitas berjalan meningkatkan bone mineral density pada perempuan pascamenopause
}

\author{
Evita Peninta Dwi Savitri ${ }^{1}$, Elly Herwana ${ }^{2}$
}

\begin{abstract}
ABSTRAK
LATAR BELAKANG

Osteoporosis merupakan penyakit tulang yang ditandai dengan rendahnya bone mineral density (BMD) disertai perubahan pada mikroarsitektur tulang. BMD yang rendah menandai adanya penurunan kepadatan pada tulang dan meningkatkan risiko terjadinya fraktur. Penurunan kadar estrogen pada kondisi pascamenopause, gaya hidup yang meliputi aktivitas fisik dan kebiasaan berjalan sangat berperanan dalam progresivitas osteoporosis. Penelitian ini bertujuan menilai hubungan antara aktivitas berjalan dengan kepadatan tulang pada perempuan pascamenopause.
\end{abstract}

\section{METODE}

Penelitian analitik observasional dengan metode cross-sectional dilakukan pada perempuan pascamenopause berusia 45-70 tahun pada periode Agustus-Oktober 2018. Penilaian aktivitas berjalan dilakukan dengan menggunakan kuesioner dan wawancara. Aktivitas berjalan dinilai dari jumlah langkah berjalan/hari yang dikonversikan dari jarak tempuh subjek berjalan kaki setiap harinya. Pengukuran BMD menggunakan calcaneal quantitative ultrasound (QUS), hasil pengukuran BMD membedakan kepadatan tulang berdasarkan nilai-T. Analisis data dilakukan dengan uji statistik Chi-square dengan tingkat kemaknaan $\mathrm{p}<0.05$.

\section{HASIL}

Sebanyak 88 perempuan pascamenopause ikut berpartisipasi sebagai subjek penelitian dengan usia (rerata \pm simpang baku) $57.91 \pm 7.25$ tahun. Distribusi aktivitas berjalan didapatkan 71 (80.7\%) kurang aktif, $12(13.6 \%)$ aktivitas sedang, dan 5 (5.7\%) aktif. Distribusi hasil penilaian kepadatan tulang didapatkan sebanyak 18 (20.5\%) normal, 49 (55.75\%) osteopenia dan 21 (23.9\%) osteoporosis. Hasil analisis statistik menunjukkan terdapat hubungan yang bermakna antara aktivitas berjalan dan kepadatan tulang pada perempuan pascamenopause $(\mathrm{p}=0.009)$.

\section{KESIMPULAN}

Terdapat hubungan yang bermakna antara aktivitas berjalan dan kepadatan tulang pada perempuan pascamenopause.

Kata kunci: aktivitas berjalan, kepadatan tulang, perempuan pascamenopause
${ }^{1}$ Program Studi Kedokteran, Fakultas Kedokteran Universitas Trisakti, Indonesia

${ }^{2}$ Departemen Farmakologi dan Farmasi Kedokteran, Fakultas Kedokteran Universitas Trisakti, Indonesia

\section{Korespondensi:}

Elly Herwana

Departemen Farmakologi dan Farmasi Kedokteran, Fakultas Kedokteran Universitas Trisakti, Indonesia

Jalan Kyai Tapa Kampus B, Grogol, Jakarta Barat 11440

Email:

elly.herwana@trisakti.ac.id

J Biomedika Kesehat 2020;3(3):119125 DOI: 10.18051/JBiomedKes.2020. v3.119-125

pISSN: 2621-539X / eISSN: 2621-5470

Artikel akses terbuka (open access) ini didistribusikan di bawah lisensi Creative Commons Attribution 4.0 International (CC-BY 4.0) 


\section{ABSTRACT}

\section{Walking activity increases bone mineral density in postmenopausal women}

\section{BACKGROUND}

Osteoporosis is a bone disease characterized by low bone mineral density (BMD) and deterioration of bone microarchitecture. Low BMD indicates a decrease in bone density and an increased risk of fracture. Decrease in postmenopausal estrogen levels, a lifestyle that includes physical activity and walking activity plays a major role in the progression of osteoporosis. This study aimed to assess the relationship between walking activity and bone density in postmenopausal women.

\section{METHODS}

An observational analytic study using a cross-sectional desain was conducted on postmenopausal women aged 4570 years in the period August-October 2018. Assessment of walking activities was carried out using questionnaires and interviews. Walking activity was assessed by the number of steps walking/day which was converted from the distance the subject walked on each day. Measurement of BMD calcaneal quantitative ultrasound (QUS), BMD measurement results differentiate bone density based on the T-value. Data analysis was performed using the Chi Square statistical test with a significance level of $\mathrm{p}<0.05$.

\section{RESULTS}

A total of 88 postmenopausal women partisipated as study subject with an age (mean \pm standard deviation) of $57.91 \pm 7.25$ years. The distribution of walking activities found $71(80.7 \%)$ less active, $12(13.6 \%)$ moderate activity, and $5(5.7 \%)$ active. The distribution of bone density assessment results showed that $18(20.5 \%)$ normal, $49(55.75 \%)$ osteopenia and $21(23.9 \%)$ osteoporosis. The results of statistical analysis showed that there was a significant relationship between walking activity and bone density in postmenopausal women $(\mathrm{p}=0.009)$.

\section{CONCLUSION}

There is a significant relation between walking activity and bone density in postmenopausal women.

Keywords: walking activity, bone density, postmenopausal women

\section{PENDAHULUAN}

Epidemiologi osteoporosis di populasi Asia cenderung mengalami peningkatan sejalan dengan peningkatan populasi lanjut usia (lansia). Cina sebagai negara dengan penduduk terbesar, diperkirakan populasi lansia akan mencapai 400 juta pada tahun 2050 dengan insiden osteoporosis mendekati $30 \%$ dari jumlah penduduknya. ${ }^{(1)}$ Hasil survei di Amerika pada periode 20052010, sebanyak 99 juta didapatkan osteopenia dan osteoporosis dan $10.3 \%$ di antaranya adalah osteoporosis. ${ }^{(2)}$ Osteoporosis yang ditandai dengan bone mineral density (BMD) yang rendah meningkatkan risiko fraktur, sekitar 50\% perempuan dan $20 \%$ laki-laki berusia di atas 50 tahun mengalami fraktur yang berkaitan dengan osteoporosis. ${ }^{(3)}$

Osteoporosis merupakan penyakit tidak menular yang memberikan dampak disabilitas dan fatalitas yang cukup tinggi.(4) Data World Health Organization (WHO) pada tahun 2009 menyatakan "osteoporosis menduduki peringkat kedua setelah penyakit jantung sebagai masalah kesehatan utama dunia."(5) Sedangkan menurut International Osteoporosis Foundation (IOF) menunjukkan bahwa "satu dari empat perempuan di Indonesia dengan rentang usia 50-80 tahun memiliki risiko terkena osteoporosis. Selain itu, risiko osteoporosis perempuan di Indonesia empat kali lebih tinggi dibandingkan laki-laki."(6)

Pembentukan tulang kembali (bone remodeling) merupakan proses aktif yang berlangsung seumur hidup, meliputi proses resorpsi dan formasi tulang yang melibatkan peran sel tulang osteoklas dan osteoblas. Ketidakseimbangan pembentukan tulang kembali yang disertai peningkatan resorpsi dan penurunan formasi tulang berakibat terjadinya defisit massa tulang dan menyebabkan terjadinya osteoporosis dan dampak dari osteoporosis adalah rendahnya massa tulang sehingga tulang menjadi rapuh dan mudah patah. ${ }^{(7)}$ Faktor risiko osteoporosis dibedakan atas faktor yang dapat dimodifikasi dan tidak dapat dimodifikasi. Faktor risiko yang tidak dapat dimodifikasi adalah genetik, pertambahan umur, jenis kelamin, serta penurunan estrogen pascamenopause. Sedangkan faktor risiko yang dapat dimodifikasi antara lain kurangnya melakukan aktivitas fisik, asupan makronutrien dan mikronutrien yang dapat mempengaruhi homeostasis mineral tulang. Mikronutrien yang paling berperan pada homeostasis mineral tulang adalah kalsium dan vitamin D. ${ }^{(8)}$ Penggunaan obat kortikosteroid jangka panjang, merokok, asupan 
alkohol dan kafein juga menjadi faktor yang memudahkan terjadinya osteoporosis. ${ }^{(9)}$

Kesehatan tulang ditentukan dari kepadatan tulang dan kualitas tulang. Kepadatan tulang menunjukkan jumlah gram mineral per volume tulang, yang dapat dinilai dengan BMD. Sedangkan kualitas tulang berkaitan dengan struktur, penghancuran, dan pembentukan tulang kembali. ${ }^{(10)}$ Hasil pengukuran kepadatan tulang dengan BMD, membedakan individu dengan kepadatan tulang normal, osteopenia dan osteoporosis berdasarkan nilai-T sebagai parameter. ${ }^{(2)}$

Beberapa studi telah dilakukan untuk menilai hubungan antara aktivitas fisik dan BMD namun belum memberikan hasil yang konklusif karena dipengaruhi oleh jenis aktivitas, frekuensi, dan durasi aktivitas fisik yang dilakukan. ${ }^{(11)}$ Terdapat penelitan yang melaporkan bahwa aktivitas berjalan kurang memberikan beban gravitasi pada tulang rangka, sehingga kurang efektif dalam pencegahan osteoporosis. ${ }^{(12)}$ Aktivitas fisik yang lebih kuat seperti aerobik dengan beban, atau latihan yang menggetarkan tubuh (whole body vibration) lebih efektif untuk mencegah osteoporosis.(12) Penelitian lainnya melaporkan bahwa selain sebagai efek stimulasi pembentukan tulang (osteoanabolik), aktivitas fisik juga bermanfaat meningkatkan kekuatan otot dan keseimbangan tubuh sehingga mencegah jatuh dan mengurangi risiko fraktur. (13) Kemampuan otot yang baik dapat membantu menyeimbangkan pergerakkan tubuh, karena mampu menopang tubuh agar tidak mudah jatuh. Wanita pascamenopause yang kurang aktif mudah mengalami kejadian atrofi otot, sehingga menyebabkan gangguan pergerakan, dan kurang mandiri karena kesulitan berdiri, risiko jatuh besar dan gerakan tubuh lambat. Penelitian ini bertujuan untuk menilai hubungan antara aktivitas berjalan dan BMD pada perempuan pascamenopause.

\section{METODE}

Penelitian ini merupakan studi analitik observasional dengan desain potong lintang (cross sectional). Penelitian ini dilaksanakan di wilayah Kelurahan Tomang, Jakarta Barat. Subjek penelitian ini adalah perempuan pascamenopause yang tinggal di kelurahan Tomang, Jakarta Barat pada bulan Agustus-Oktober 2018.
Pemilihan subjek penelitian menggunakan teknik consecutive non random sampling. Kriteria inklusi penelitian ini adalah perempuan berusia 45-70 tahun, telah mengalami menopause (henti haid) selama satu tahun atau lebih, mampu berjalan dan berkomunikasi, bersedia berpartisipasi, dan menandatangani informed concent. Kriteria eksklusi penelitian ini adalah perempuan menopause non-alamiah (akibat pengangkatan rahim, penyakit, obat-obatan), mempunyai riwayat penyakit keganasan, mengonsumsi obat/ suplemen yang dapat memengaruhi metabolisme tulang (kortikosteroid jangka panjang, kalsium, vitamin $\mathrm{D}$, dan isoflavon).

Perhitungan jumlah sampel dilakukan dengan menggunakan rumus perbedaan proporsi. Rumus yang digunakan adalah sebagai berikut:

$$
\mathrm{N}=\mathrm{Z} \alpha^{2}(\mathrm{p} \times \mathrm{x}) / \mathrm{d}^{2}
$$

Data prevalensi perempuan pascamenopause dengan osteoporosis di Indonesia yaitu sebesar $32.2 \%$, dengan tingkat kemaknaan sebesar 95\%. Maka didapati perhitungan jumlah sampel sebanyak 336 subjek penelitian. Pencatatan data untuk jumlah perempuan pascamenopause di kelurahanTomang, Jakarta Barat yaitu terdapat 100 orang, dengan menambahkan perhitungan dropout sebesar $15 \%$, maka jumlah sampel yang dibutuhkan yaitu sebanyak 88 subjek.

Penilaian untuk aktivitas berjalan diperoleh melalui pengisian kuesioner disertai wawancara pada subjek. Aktivitas berjalan dinilai dengan menghitung jumlah langkah berjalan yang dikonversi dari jarak tempuh subjek berjalan sehari-hari yang menjadi kebiasaan hidupnya. Evaluasi aktivitas berjalan dilakukan untuk tujuh hari meliputi hari kerja dan hari libur, lalu dihitung rerata per hari. Jarak tempuh diperhitungkan dalam meter, kemudian dikonversikan sebagai 3 langkah/meter sehingga didapatkan total jumlah langkah/hari. Berdasarkan jumlah langkah/hari, subjek dibedakan atas 3 kategori yaitu aktivitas berjalan kurang apabila nilainya $<7.500$ langkah/ hari, sedang untuk 7.500-10.000 langkah/hari, dan aktif untuk nilai $>10.000$ langkah/hari.

Kepadatan tulang dari setiap subjek dinilai menggunakan alat calcaneal quantitative ultrasound (QUS), yang dalam penggunaannya dibantu oleh tenaga ahli yang berkompeten. 
Kepadatan tulang diukur dinyatakan dengan nilai-T untuk menetapkan kategorinya. Selanjutnya subjek penelitian dikelompokkan menjadi 3 kategori yaitu kepadatan tulang normal bilamana nilai- $\mathrm{T} \geq-1 \mathrm{SD}$, osteopenia dengan nilai-T antara -1 sampai -2.5 (nilai-T $>-1$ - >-2.5) $\mathrm{SD}$ dan osteoporosis dengan nilai- $\mathrm{T} \leq 2.5 \mathrm{SD}$.

Analisis statistik mengunakakan uji $C h i$ Square dan uji Fisher dengan batas kemaknaan sebesar $\mathrm{p}<0.05$ digunakan untuk menilai hubungan antara aktivitas berjalan dengan BMD pada perempuan pascamenopause. Penelitian ini telah lulus kaji etik dari Komisi Etik Penelitian Fakultas Kedokteran Universitas Trisakti dengan Nomor 76/KER-FK/VIII/2018.

\section{HASIL}

Sebanyak 88 subjek perempuan pascamenopause usia 45-70 tahun telah berpartisipasi dalam penelitian ini. Usia subjek paling muda adalah 45 tahun dan usia paling tua adalah 70 tahun dan rerata usia \pm simpang baku adalah $57.91 \pm 7.25$ tahun. Distribusi karakteristik subjek studi dapat dilihat pada Tabel 1.

Tabel 1. Distribusi karakteristik subjek penelitian $(\mathbf{n}=\mathbf{8 8})$

\begin{tabular}{lll}
\multicolumn{1}{c}{$\begin{array}{c}\text { Karakteristik } \\
\text { responden }\end{array}$} & Rerata \pm SD & n (\%) \\
\hline $\begin{array}{ll}\text { Usia(tahun) } \\
\text { Lama menopause }\end{array}$ & $57.91 \pm 7.25$ & \\
$1-5$ tahun & $43(48.9)$ \\
$>5$ tahun & $45(51.1)$ \\
Jumlah langkah/hari & \\
Kurang $(<7500)$ & $71(80.7)$ \\
Sedang $(7500-10.000)$ & $12(13.6)$ \\
Aktif $(>10.000)$ & $5(5.7)$ \\
Kepadatan tulang & $18(20.5)$ \\
Normal $(\geq-1 \mathrm{SD})$ & $49(55.7)$ \\
Osteopenia $(-1>->-2.5$ & \\
SD) & $21(23.9)$ \\
Osteoporosis $(\leq-2.5$ SD) & \\
\hline
\end{tabular}

$\mathrm{n}=$ frekuensi; $\%=$ persentase

Distribusi aktivitas berjalan subjek terbanyak adalah dari kelompok kurang dan meliputi $80.7 \%$ dari subjek dan hanya 5.7\% yang tergolong aktif. Hasil pengukuran BMD menunjukkan distribusi kepadatan tulang terbanyak adalah kelompok osteopenia yang meliputi lebih dari separuh subjek $(55.7 \%)$ dan hanya 20.5\% menunjukkan BMD normal. (Tabel 1)

Lama menopause subjek dikategorikan dengan batasan titik potong lima tahun atas pertimbangan bahwa lima tahun awal menopause mempunyai karakteristik gejala dan dampak osteoporosis pascamenopause yang berbeda dengan lebih dari 5 tahun pascamenopause. (14) Distribusi jumlah subjek berdasarkan lama menopause menunjukkan jumlah yang seimbang. Tampak kecenderungan peningkatan proporsi osteoporosis sejalan dengan pertambahan usia dan lama menopause. Hasil analisis hubungan antara lama menopause dan kepadatan tulang dengan uji Chi Square menunjukkan adanya perbedaan yang bermakna untuk lama menopause kurang dari lima tahun dan sesudah lima tahun. (Tabel 2)

Analisis hubungan aktivitas berjalan dan kepadatan tulang menggunakan uji Fisher dengan dua kelompok kategori yaitu aktivitas berjalan kurang aktif dan aktif dengan titik potong 7500 langkah/hari. Sementara kepadatan tulang menjadi kategori tidak osteoporosis dan osteoporosis dengan titik potong $T$-score 2.5. Hasil analisis uji Fisher didapatkan hubungan yang bermakna antara aktivitas berjalan dan kepadatan tulang. (Tabel 2)

\section{PEMBAHASAN}

Hasil pengukuran BMD pada penelitian ini didapatkan frekuensi terbanyak adalah perempuan pascamenopause dengan osteopenia yang meliputi lebih dari seperuh (55.7\%) subjek. Hasil penelitian ini sejalan dengan beberapa penelitan yang menunjukkan hasil yang serupa, yaitu bahwa osteopenia meliputi sekitar separuh dari disttibusi BMD pada perempuan pascamenopause. ${ }^{(2,14)}$ Perempuan pascamenopause dengan osteoporosis pada penelitian ini didapatkan sebanyak 21 (23.9\%), data ini sesuai dengan prevalensi osteoporosis di Indonesia sebagaimana dilaporkan dari pusat data dan informasi Kementerian Kesehatan Republik Indonesia. Proporsi osteoporosis didapatkan satu dari empat perempuan di atas usia 50 tahun, prevalensi osteoporosis juga dilaporkan meningkat sejalan dengan pertambahan usia dan meningkat menjadi lebih dari 50\% pada usia 75-80 tahun ${ }^{(6)}$ Penelitian sebelumnya mendapatkan bahwa peningkatan prevalensi osteoporosis pascamenopause berkaitan dengan penurunan kadar estrogen. ${ }^{(7,15)}$ Pada masa transisi menopause, perempuan kehilangan sekitar 10\% BMD dan sekitar separuh di antaranya terjadi 
Tabel 2 . Hubungan antara lama menopause dan aktivitas berjalan dengan kepadatan tulang $(\mathbf{n}=\mathbf{8 8})$

\begin{tabular}{|c|c|c|c|c|}
\hline \multirow[b]{2}{*}{ Variabel } & \multicolumn{3}{|c|}{ Kepadatan Tulang } & \multirow[b]{2}{*}{ p value } \\
\hline & $\begin{array}{c}\text { Normal } \\
\text { n (\%) }\end{array}$ & $\begin{array}{l}\text { Osteopenia } \\
\text { n (\%) }\end{array}$ & $\begin{array}{c}\text { Osteoporosis } \\
\text { n (\%) }\end{array}$ & \\
\hline $\begin{array}{l}\text { Lama menopause } \\
1-5 \text { tahun }\end{array}$ & $14(32.6)$ & $26(60.5)$ & $3(7.0)$ & $0.00^{*}$ \\
\hline$>5$ tahun & $4(8.9)$ & $23(51.1)$ & $18(40.0)$ & \\
\hline \multicolumn{5}{|l|}{ Aktivitas berjalan } \\
\hline Kurang & 1 & 48 & 21 & $0.009^{* *}$ \\
\hline Sedang & 12 & 1 & 0 & \\
\hline Aktif & 5 & 0 & 0 & \\
\hline
\end{tabular}

${ }^{*}$ Uji Chi Square, $\mathrm{p}<0.05$ berbeda bermakna; ${ }^{* *}$ Uji Fisher, $\mathrm{p}<0.05$, berbeda bermakna

percepatan penurunan BMD pada 5-6 tahun pascamenopause. ${ }^{(16)}$ Hasil penelitian lain juga menunjukkan terjadinya tendensi peningkatan proporsi osteoporosis sejalan dengan pertambahan usia. ${ }^{(14)}$ Hasil penelitian ini menunjukkan tendensi peningkatan proporsi osteoporosis sejalan dengan pertambahan usia, terdapat perbedaan yang bermakna antara lama menopause dan BMD.

Hasil penelitian ini menunjukkan terdapat hubungan bermakna antara aktivitas berjalan dan BMD pada perempuan pascamenopause $(p=0.009)$. Banyak penelitian telah dilakukan untuk menilai hubungan antara aktivitas fisik dan BMD, namun hasilnya sangat bervariasi karena sangat dipengaruhi oleh jenis aktivitas, frekuensi dan durasi aktivitas fisik yang dilakukan. ${ }^{(12,13,17,18)}$ Terdapat penelitian yang melaporkan bahwa atlit renang dan pesepeda menunjukkan BMD yang lebih rendah daripada atlit olah raga repetitif yang menggunakan beban berat badan seperti aerobik. Aktivitas fisik tanpa beban berat badan (non-weight bearing sports) memperkuat otot tetapi tidak memberikan kekuatan dampak (impact), hal ini menandai bahwa dampak beban gravitasi lebih berperan untuk stimulasi tulang. ${ }^{(12)}$ Olahraga dengan beban berat badan menunjukkan peningkatan kepadatan tulang di area kortikal dan kolum femoris. Penelitian lainnya menunjukkan aktivitas fisik tingkat tinggi pada atlit perempuan yang dilakukan di masa muda berhubungan dengan peningkatan massa otot dan BMD serta bermanfaat mencegah kehilangan massa tulang yang berkaitan dengan pertambahan usia. ${ }^{(18)}$

Hasil penelitian ini mendapatkan subjek kelompok aktif dalam aktivitas berjalan berhubungan dengan BMD yang lebih tinggi. Aktivitas berjalan dapat meningkatkan BMD kolum femoris tetapi tidak untuk BMD vertebra pada permpuan pascamenopause. Kombinasi program latihan kombinasi dengan aerobik dan dampak lebih direkomendasikan untuk meningkatkan BMD vertebra. ${ }^{(13)}$ Penelitan lainnya juga melaporkan bahwa aktivitas berjalan tidak memberikan efek bermakna pada BMD di vertebra, radius, atau keseluruhan BMD pada perempuan perimenopause maupun pascamenopause, tetapi memberikan efek bermakna peningkatan BMD kolum femoris pada intervensi berjalan selama 6 bulan. ${ }^{(19)}$ Penelitian serupa melaporkan bahwa aktivitas berjalan memberikan efek perubahan yang terbatas terhadap BMD, aktivitas fisik dengan beban dan dampak memberikan perubahan BMD yang lebih besar. ${ }^{(20)}$ Studi lainnya dengan meta-analisis mendapatkan bahwa aktivitas fisik menunjukkan perbedaan yang bermakna pada BMD kolum femoris dan BMD vertebra pada perempuan pascamenopause. ${ }^{(10)}$

Penelitian ini menilai hubungan aktivitas berjalan terhadap BMD berdasarkan kebiasaan berjalan berdasarkan kegiatan yang dilakukan setiap hari dan bukan sebagai olah raga. Aktivitas berjalan yang dilakukan sebagai kebiasaan rutin ternyata menunjukkan perbedaan yang bermakna pada BMD yang dilakukan di tulang tumit dengan calcaneal quantitative ultrasound (QUS) BMD.

Sebagian besar penelitian menilai kepadatan tulang menggunakan dual-energy $X$-ray absorptiometry (DXA), sehingga dapat memberikan gambaran BMD yang menyeluruh meliputi nilai-T pada kolum femoris, vertebra dan radius. Penelitian ini memiliki keterbatasan karena menggunakan QUS yang hanya memberikan gambaran nilai-T pada tulang rumit. Meskipun demikian, terdapat penelitian yang melaporkan 
bahwa QUS menunjukkan sensitivitas yang tinggi untuk mendeteksi BMD yang rendah dibandingkan pemeriksaan dengan DXA, sehingga dapat digunakan untuk mendeteksi peningkatan risiko osteoporosis. $^{(21)}$

Banyak penelitian telah dilakukan untuk menemukan mekanisme seluler tentang pengaruh aktifitas fisik terhadap BMD. ${ }^{(22)}$ Banyak teori dikemukakan mengenai keterlibatan sel osteosit, stimulasi osteoblas dalam remodeling tulang, namun hasilnya belum konklusif sehingga diperlukan penelitian lebih lanjut yang dapat menjelaskan patofisiologi osteoseluler yang terjadi pada osteoporosis. ${ }^{(17,22)}$

\section{KESIMPULAN}

Terdapat hubungan yang bermakna antara antara aktivitas berjalan dan kepadatan tulang pada perempuan pascamenopause.

\section{UCAPAN TERIMA KASIH}

Ucapan terima kasih kepada perempuan pascamenopause yang telah bersedia untuk berpartisipasi sebagai subjek penelitian dan kepada pimpinan kelurahan Tomang beserta jajarannya yang telah memfasilitasi pelaksanaan penelitian ini.

\section{KONFLIK KEPENTINGAN}

Semua peneliti tidak memiliki konflik kepentingan terhadap hasil penelitian ini

\section{REFERENSI}

1. Cheung EYN, Tan KCB, Cheung CL, et al.Osteoporosis in East Asia: Current issues in assessment and management. Osteoporos Sarcopenia. 2016;2:118-33. doi:10.1016/j. afos.2016.07.001

2. Wright NC, Looker AC, Saag KG, et al. The Recent Prevalence of Osteoporosis and Low Bone Mass in the United States Based on Bone Mineral Density at the Femoral Neck or Lumbar Spine. J Bone Miner Res. 2014;29:2520-6. doi:10.1002/ jbmr.2269

3. Coughlan T, Dockery F. Osteoporosis and fracture risk in older people. Clin Med. 2014;14:187-91. doi: 10.7861/clinmedicine.14-2-187

4. Amiri AM, Hosseini SR, Rahmaninia F, et al. Relationship between Bone Mineral Density and Physical Activity Level in the Elderly. Ann Appl Sport Sci. 2015;3(2):23-32. doi: 10.18869/ acadpub.aassjournal.3.2.23

5. Carter MI, Hinton PS. Physical activity and bone health. Mo Med. 2014 Jan-Feb;111(1):59-64. PMID: 24645301; PMCID: PMC6179512

6. Pusat Data dan Informasi Kementerian Kesehatan
RI. Data dan Kondisi Penyakit Osteoporosis di Indonesia [Internet]. Jakarta: Pusat Data dan Informasi Kementerian Kesehatan RI; 2015. Available from: https://www.kemkes.go.id/ resources/download/pusdatin/infodatin/infodatinosteoporosis.pdf

7. Gallangher JC, Tella SH. Prevention and treatment of postmenopausal osteoporosis. J Steroid Biochem Mol Biol. 2014;142:155-70. doi:10.1016/j.jsbmb.2013.09.008

8. Chiodini I, Bolland MJ. Calcium supplementation in osteoporosis: useful or harmful? Eur J Endocrinol. 2018;178:D13-D25. doi:10.1530/ EJE-18-0113

9. Quesada Gómez JM, Blanch Rubió J, Díaz Curiel M, Díez Pérez A. Calcium citrate and vitamin D in the treatment of osteoporosis. Clin Drug Investig. 2011;31(5):285-98. doi: 10.1007/BF03256927

10. Kelley GA, Kelley KS, Kohrt WM. Exercise and bone mineral density in premenopausal women: a meta - analysis of randomized controlled trials. Internl J Endocrinol. 2013:741639 ID Article741639. 16 pages. doi: 741639/2013/1155.10/org.d

11. Benedetti MG, Furlini G, Zati A et al. The Effectiveness of Physical Exercise on Bone Density in Osteoporotic Patients. Biomed Res Int. 2018. Article ID 4840531, 10 pages. doi: $10.1155 / 2018 / 4840531$

12. Gómez-Cabello A, Ara I, González-Agüero A, et al. Effects of training on bone mass in older adults: a systematic review. Sports Med. 2012 Apr 1;42(4):301-25. doi: 10.2165/11597670$000000000-00000$

13. Moreira LD, Oliveira ML, Lirani-Galvão AP, et al. Physical exercise and osteoporosis: effects of different types of exercises on bone and physical function of postmenopausal women. Arq Bras Endocrinol Metabol. 2014 Jul;58(5):514-22. doi: 10.1590/0004-2730000003374. PMID: 25166042

14. Kaushal N, Vohora D, Jalali RK, et al. Prevalence of osteoporosis and osteopenia in an apparently healthy Indian population - a cross-sectional retrospective study. Osteoporos Sarcopenia. 2018;4: 53-60. doi.org/10.1016/j.afos.2018.04.002

15. Iqbal J, Zaidi M. Understanding Estrogen Action during Menopause. Endocrinology 2009;150:3443-45. doi: 10.1210/en.2009-0449

16. Ji MX, Yu Q. Primary osteoporosis in postmenopausal women. Chronic Dis Transl Med. 2015;1:9-13. doi:10.1016/j. cdtm.2015.02.006

17. Nikander R, Kannus P, Dastidar P, et al. Targeted exercises against hip fragility. Osteoporos Int. 2009 Aug;20(8):1321-8. doi: 10.1007/s00198008-0785-X

18. Andreoli A, Celi M, Volpe SL, et al. Long-term effect of exercise on bone mineral density and body composition in post-menopausal ex-elite athletes: a retrospective study. Eur J Clin Nutr. 2012;66:6974. doi:10.1038/ejen.2011.104

19. Ma D, Wu L, He Z. Effects of walking on the preservation of bone mineral density in perimenopausal and postmenopausal women: a systematic review and meta-analysis. Menopause. 2013;20:1216-26. doi: 10.1097/ gme.000000000000010

20. Bolam KA, van Uffelen JGZ, Taaffe DR. The effect of physical exercise on bone density in middle-aged and older men: A systematic review. 
Osteoporos Int. 2013;24:2749-62. doi: 10.1007/ s00198-013-2346-1

21. Boban A, Zupancic Salek S, Kastelan D, et al. Quantitative ultrasound and dual energy X-ray absorptiometry in the assessment of osteoporosis in patients with haemophilia. Haemophilia. 2014 Nov;20(6):e420-2. doi: 10.1111/hae.12529

22. Tobeiha M, Moghadasian MH, Amin N, et al. RANKL/RANK/OPG Pathway: A Mechanism Involved in Exercise-Induced Bone Remodeling. Biomed Res Int. 2020 Feb 19;2020:6910312. doi: $10.1155 / 2020 / 6910312$ 